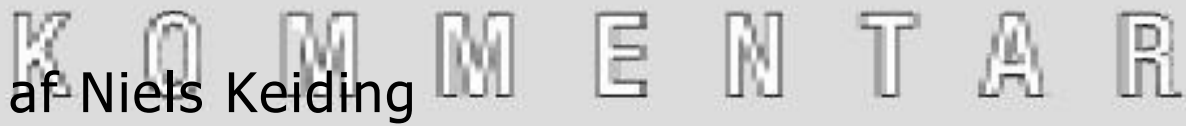

\section{Kan vi løfte arven efter Westergaard?}

Harald Westergaard (1853-1936) var uddannet mag.scient. i matematik og cand.polit. og var professor i statsvidenskab ved Københavns Universitet fra 1886 til 1924. Westergaards forfatterskab var meget omfattende, og betydelige dele af det beskæftigede sig med, hvad vi nu om dage betegner som demografi.

I 1881 tildeltes han universitetets guldmedalje for sin besvarelse af prisopgaven "Der ønskes en fremstilling og vurdering af de i den nyere tid fremkomne undersøgelser om dødeligheden i forskellige samfundsklasser". En tysk oversættelse udkom snart under titlen "Die Lehre von der Mortalität und Morbilität" (Westergaard 1882) på over 500 sider. Bogen, som udkom i stærkt revideret og udvidet udgave i 1901 (Westergaard 1901), indeholder først og fremmest en stor mængde konkrete fakta fra mange lande om sygelighed og dødelighed i de forskellige erhverv, men også en række interessante metodebetragtninger. Allerede i indledningen drøfter Westergaard spørgsmålet om danske lægers dødelighed i forhold til normalbefolkningen på basis af opstillingen i Tabel 1. Westergaard beregner her det "forventede antal døde" læger, dvs. hvor mange læger, der ville være døde, hvis befolkningens aldersspecifikke dødelighedsrater havde været gældende for lægerne - vi vil nu om dage tale om indirekte standardisering. Beregningen gennemførtes dels ved at sammenligne med befolkningsdødeligheden i København, provinsbyer og landdistrikter separat, dels ved at sammenligne med befolkningsdødeligheden i hele landet. Forskellen er dramatisk: i det første tilfælde ses lægerne at have en underdødelighed i byerne og en overdødelighed på landet, ifølge den anden beregning synes læger at have en overdødelighed over hele landet. Westergaard anser den distriktsopdelte analyse for den korrekte, idet man ellers ser bort fra den betydelige variation af dødelighed med distrikt; vi ville sige at man ikke har foretaget den fornødne konfounderkorrektion. En oversigt over de "forventede antal døde"s historie er givet af Keiding (1987).

Selvom J. B. S. Estrup var konseilspræsident gennem hele Westergaards 


\begin{tabular}{ccccc}
\hline & & \multicolumn{3}{c}{$\begin{array}{c}\text { Erwartungsmässig } \\
\text { Gestorbene nach }\end{array}$} \\
Aufenthaltsort & Lebensjahre & Gestorbene & $\begin{array}{r}\text { den 3 } \\
\text { speciellen } \\
\text { Tafeln }\end{array}$ & $\begin{array}{r}\text { Königreichs } \\
\text { der Tafel } \\
\text { des }\end{array}$ \\
& & & 156 & 98 \\
Kopenhagen & 7127,0 & 108 & 183 & 143 \\
Provinzstädte & 9556,5 & 159 & 53 & 60 \\
Landdistricte & 4213,5 & 74 & 392 & 301 \\
\hline Ganzes Land & 20897,0 & 341 & & \\
\hline
\end{tabular}

Oversættelse: Lebensjahre: personår under risiko

Gestorbene: antal døde

Erwartungsmässig Gestorbene: forventet antal døde den 3 speciellen Tafeln: de 3 specifikke (dødeligheds)tavler der Tafel des Königreichs: (dødeligheds)tavlen for hele landet

ungdom, fik Westergaard god lejlighed til at dyrke sine socialpolitiske interesser. Sammen med den jævnaldrende cand.polit. Marcus Rubin (1854-1923) gennemførte Westergaard først på opfordring af nationalbankdirektør Moritz Levy en undersøgelse af "Landbefolkningens Dødelighed i Fyens Stift" (Rubin \& Westergaard 1886), som var metodisk imponerende derved, at degnene tilvejebragte både tæller- og nævnerpopulationerne, og at bearbejdelsen derefter konsekvent anvendte de forventede antal dødes metode. Arbejdet var beregnet til at indgå som baggrundsmateriale i den daværende politiske debat om alderdomsforsørgelsesspørgsmålet, og i indledningen kridter forfatterne banen fyndigt op:

Medens det hidtil gældende Hovedprincip ved Behandlingen af de sociale Spørgsmaal var Selvhjælpsprincipet, er man saaledes, ved at Staten har stillet sig i Breschen, gaaet bort fra den Individualisme, der var det afgørende i den gamle Nationaløkonomi. Man indrømmer - enten ligeud eller indirekte - at Samfundsordningen medfører saa megen Ubillighed, at det hele Samfund som saadant maa søge at raade Bod derpaa overfor dem, der lide under Ubilligheden, og den støtte, Staten da vil give, bliver herved Fyldestgørelsen af en Forpligtelse fra Statens, Modtagelsen af en Ret fra Arbejdernes Side.

Dødeligheden opstilles separat for personer "I Virksomhed" og "Udenfor Virksomhed" og efter erhverv. Hovedresultaterne bedømmes ved de beregnede dødes metode: 
Denne Tavle frembyder mange mærkelige Forhold. Medens Embedsklassen (Skolelærere og Bestillingmænd iberegnet) omtrent har samme Dødelighed som Befolkningen som Helhed, viser det sig, at Handelsstanden snarest har ringere Dødelighed, og at Haandværksstanden har udpræget gunstigere Sundhedsforhold end den almindelige Befolkning, hvilket ogsaa gælder om Fiskerne, baade Mænd og Kvinder. Derimod udmærker Gaardmandsklassen sig ingenlunde ved gunstige Sundhedsforhold, den kan omtrent stilles lige med Husmænd med Jord, medens atter Husmænd uden Jord ere ugunstigere stillede. Tyendeklassens gunstige Dødelighedsforhold ere ovenfor omtalte. Hvad endelig Fattiglemmers Dødelighed angaar, er denne vel høj, i det mindste blandt Mænd, men man vilde maaske have ventet en endnu større Dødelighed; det skal nedenfor paavises, hvorledes det kun er enkelte Aldersklasser, i hvilke Fattiglemmerne have en særlig stor Dødelighed.

Arbejdet vakte Estrups interesse i den grad, at staten støttede en opfølgende undersøgelse "Ægteskabsstatistik efter den sociale Lagdeling" (Rubin \& Westergaard 1890), som var teknisk baseret på særlige kolonner, som Rubin i sin egenskab af chef for Københavns Kommunes statistiske kontor havde fået tilføjet folketællingsskemaerne for 1880 :

Forsaavidt Vedkommende er gift, Enkemand, Enke, Fraskilt, ønskes besvaret:

a) om første eller anden Gang gift;

b) om hvilket Aar der er indgaaet $Æ g t e s k a b$;

c) om Antallet af levende Børn i Ægteskabet;

d) om Antallet af døde Børn, indbefattet dødfødte, i Ægteskabet.

(Oplysningerne b-d gælde udelukkende for sidste Ægteskab).

Rubin og Westergaard publicerer her den formentlig første undersøgelse nogensinde af nuptialitet og fertilitet efter socioøkonomiske determinanter. For København er det et centralt resultat, at af de fem samfundslag har de øverste og nederste den største "Produktivitet", mens den midterste gruppe "Lærere, Musikere, Kontorister, Handelsmedhjæpere, Assistenter i offentlige Kontorer o.lign." har den mindste. Forfatterne anvender igen, til tider helt virtuost, de beregnede tilfældes metode. En charmerende smagsprøve fremgår af Tabel 2 , som skal besvare spørgsmålet, hvorvidt "Enkemænd, naar de gifte sig, særlig søge at blive gifte med Enker, og at Ungkarle og Piger søge hverandre“. Det fremgår af tabellen, at 240 af 1.286 viede enkemænd giftede sig med enker, mens kun 470 af 10.263 ungkarle som giftede sig, giftede sig med enker. Vi giver ordet til Rubin og Westergaard vedrørende Tabel 2: 


\begin{tabular}{|c|c|c|c|c|c|c|c|c|c|c|}
\hline Alder & 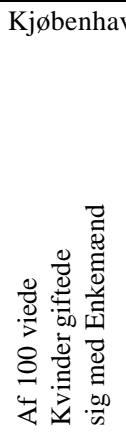 & $\begin{array}{l}\text { Af Enl } \\
\text { sig me } \\
\text { Enken } \\
\text { efter } \\
\\
\text { Er- } \\
\text { faring }\end{array}$ & $\begin{array}{l}\text { er giftede } \\
\text { end }\end{array}$ & $\begin{array}{l}\text { Af Pig } \\
\text { sig me } \\
\text { Enkem } \\
\text { efter }\end{array}$ & $\begin{array}{l}\text { giftede } \\
\text { nd }\end{array}$ & 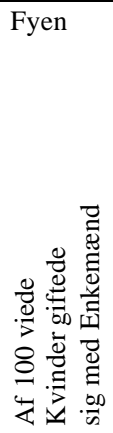 & $\begin{array}{l}\text { Af Enk } \\
\text { sig me } \\
\text { Enkem } \\
\text { efter }\end{array}$ & $\begin{array}{l}\text { giftede } \\
\text { nd } \\
\text { Be- } \\
\text { regning }\end{array}$ & $\begin{array}{l}\text { Af Pige } \\
\text { sig med } \\
\text { Enkem } \\
\text { efter }\end{array}$ & $\begin{array}{l}\text { giftede } \\
\text { nd }\end{array}$ \\
\hline 16-19 Aar & 6,2 & - & - & 43 & 43 & 4,1 & - & - & 9 & 9 \\
\hline $20-24-\ldots$ & 4,7 & 1 & 1 & 199 & 198 & 4,0 & 1 & 0 & 75 & 75 \\
\hline $25-29-\ldots$ & 6,8 & 16 & 7 & 225 & 233 & 5,1 & 2 & 2 & 110 & 110 \\
\hline $30-34-\ldots$. & 16,0 & 37 & 25 & 233 & 245 & 12,6 & 5 & 6 & 132 & 131 \\
\hline $35-44-$ & 34,3 & 111 & 100 & 281 & 292 & 27,2 & 38 & 43 & 161 & 156 \\
\hline 45 Aar og derover & 54,9 & 75 & 73 & 65 & 68 & 57,4 & 70 & 76 & 69 & 63 \\
\hline Tilsammen ... & 11,1 & 240 & 206 & 1046 & 1079 & 10,6 & 116 & 127 & 556 & 544 \\
\hline
\end{tabular}

De "beregnede" Tal angive det Antal Vielser mellem Enker og Enkemænd, som skulde have fundet Sted, hvis disse Vielser være foregaaede i samme Omfang, som Procenttallene angive for samtlige Vielser, de "erfarede" Tal angive det faktiske Antal Vielser mellem Enker og Enkemænd.

Det vil sees af Tavlen, at der ingen væsentlig Forskel er mellem Enkemændenes Tilbøjelighed til at gifte sig med Enker og Piger, navnlig ikke paa Fyen. I Kjøbenhavn er der vel et lidt større faktisk Antal, end man skulde have ventet, men i Sammenligning med Middelfejlen er Forskellen dog ikke saa stor, at man tør bygge videre derpaa, og den er ganske betydningsløs ligeoverfor den store Forskel, man finder ved den almindelig benyttede summariske Methode.

Ikke alene anvendes her indirekte standardisering, denne sammenlignes endda med "middelfejlen", som Westergaard havde medtaget i sin monografi fra 1882. I epidemiologisk litteratur tilskrives den almindeligvis englænderen G. U. Yule (1934) i hans store afhandling om standardisering.

Af stor interesse for nutidig forskning blandt epidemiologer ved Syddansk Universitet i Odense og ved Max-Planck-Institut für Demografische Forschung i Rostock er, at Westergaard (1898) i arbejdet "Oldingealderens Dødelighed" først tilrådede stor omhu med datagrundlaget for de højeste aldre og dernæst 
gav en meget indsigtsfuld og nuanceret fremstilling af de heterogenitets- og selektionsforhold, som nu til dags i skikkelse af frailty-modeller (Vaupel et al. 1979) danner baggrund for forståelse af den dæmpede stigning af populationsdødeligheden i de højeste aldre.

Ved den hidtil eneste københavnske session i International Statistical Institute i 1907 holdt Westergaard (1908) et foredrag med titlen: "The Horoscope of the Population in the Twentieth Century", som blev publiceret i 1908. Westergaards dybe empiriske indsigt i fertilitets- og mortalitetstendenserne muliggjorde, at han her klart kunne forudse forløbet af og konsekvenserne af, hvad vi nu kalder den demografiske transition.

... We shall not have the age distributions of former days, population will have an entirely different appearance, with its big numbers of old people and its relatively small numbers of young persons.

Hans bidrag til befolkningsfremskrivninger var metodisk beskedent, men konceptuelt vigtigt (de Gans 1999).

Figur 1. Lexis-diagram (Westergaard \& Nybølle 1927, Fig. 15)

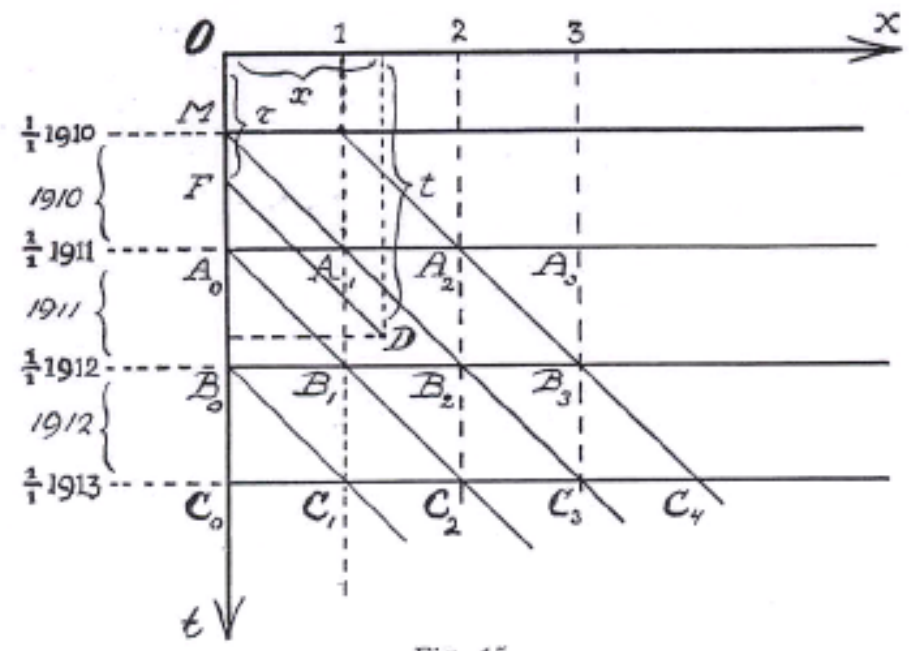

Fig. 15.

I tredje udgave af sin lærebog om statistik (1927) samarbejdede Westergaard med sin efterfølger H. C. Nybølle, og de publicerede den først kendte lærebogsversion af det nu om dage anvendte Lexis-diagram, nemlig et diagram mellem kalendertid og alder, se Fig. 1. Lexis selv brugte et diagram med fødselsår som x-akse og alder som y-akse, se nærmere Keiding $(1990,2000)$. 


$\left.\begin{array}{|l}\text { DETERMINANTER } \\ \text { фkonomiske } \\ \text { sociale } \\ \text { adfærds } \\ \text { biologiske }\end{array}\right\} \quad\left\{\begin{array}{l}\text { DESKRIPTION } \\ \text { familiedannelse } \\ \text { fertilitet } \\ \text { vandringer } \\ \text { dødelighed }\end{array}\right\} \quad\left\{\begin{array}{l} \\ \text { konsekvenser } \\ \text { for samfundet }\end{array}\right.$

\section{Dansk demografi i dag som set fra en interesseret ekstern iagttager}

Som udefra kommende iagttager af demografi opfatter jeg faget som skitseret Figur 2. I centrum står den deskriptive demografi med disciplinerne familie dannelse, fertilitet, vandringer og dødelighed. Rigtigt spændende bliver det først, når disse deskriptive discipliner relateres til sociale (herunder økonomiske), adfærdsmæssige og biologiske determinanter, og når de demografiske fakta udmøntes i prognoser og andre konsekvensberegninger til belysning af demografiens dynamik i forhold til samfundet.

Dansk demografi befinder sig i øjeblikket i en ejendommelig situation, med kun ganske enkelte egentlige demografer og med begrænset international gennemslagskraft. Uden at prætendere at give en udtømmende oversigt vil jeg i det følgende forsøge at påvise, at der ikke desto mindre er et stort potentiale både i datagrundlag og i nærtliggende forskningsressourcer, som bør kunne aktiveres, så Danmark kan vende tilbage til sin førerstilling fra Westergaards tid.

De centrale deskriptive discipliner vedligeholdes i dansk demografi først og fremmest af Danmarks Statistik, som i de senere år supplerer den løbende statistikproduktion med den centrale redaktionelle bearbejdning af de individuelle mikrodata til den "Demografiske Database" (Petersen 2000), hvor de demografiske begivenheder kobles longitudinelt for hvert individ. Danmarks Statistik har stået for andre vigtige oparbejdninger, først og fremmest Fertilitetsdatabasen (Knudsen 1993, 1998), men også undersøgelser siden 1980'erne om dødelighed og erhverv (f.eks. Andersen 1985, Andersen et al. 2001) og en meget omhyggelig oparbejdning af forløbsdata for højere uddannelse (Zangenberg \& Zeuthen 1997). Deskriptive demografiske studier trives også i Statens Institut for Folkesundhed, som huser Dødsårsagsregisteret, se Juel (2004), og som deltog energisk i middellevetidsudredningerne. En aktuel ph.d.-afhandling af Jacobsen (2004), jf. Jacobsen et al. $(2002,2004)$ fokuserer på kohorteeffekter af kvinders dødelighed. 
Analytiske mikrodatastudier i økonometri og epidemiologi ligger i mange tilfælde så tæt på analytisk demografi (se venstre side af Fig. 2), at distinktionen opløses i valg af terminologi. Det gælder omfattende studier f.eks. af determinanter for arbejdsløshed ved det tidligere Center for Arbejdsmarkedsstudier ved Aarhus Universitet og Handelshøjskolen i Århus, og det gælder Center for Anvendt Mikroøkonometri ved Københavns Universitet, som anvender konkrete økonomiske forklaringsmodeller for demografiske begivenheder, f.eks. fertilitet (Ejrnæs \& Pörtner 2002), tilbagetrækning fra arbejdsmarkedet (Danø et al. 2004), arbejdsløshedsgenereret sygelighed (Browning et al. 2003).

I epidemiologi forekommer selvsagt en lang række opgørelser af incidens, letalitet og mortalitet af enkeltsygdomme, også ofte på basis af befolkningsdata. Det epidemiologiske forskningsmiljø er spredt ud over en række sundhedsvidenskabelige universitetsinstitutter, andre offentlige og private forskningsinstitutioner og Center for Registerforskning ved Aarhus Universitet. Som eksempler på undersøgelser af speciel demografisk interesse kan nævnes paritetens (dvs. barnets nummer i søskendeflokken) betydning for barnets risiko for at udvikle kræft (Westergaard et al. 1998) eller graden af moderens brystkræft (Wohlfahrt et al., 1999).

En ny interesse for mulige biologiske determinanter i fertilitetstrends (Jensen et al. 2002) vil kræve intensivt samarbejde med de traditionelle demografiske socioøkonomiske og adfærdsmæssige forklaringsmodeller.

Dansk biostatistik har i en lang årrække bidraget med vigtige værktøjer til analyse af overlevelsesdata konkret f.eks. udmøntet i tre doktorafhandlinger (Hougaard 1995, Andersen 1997, Scheike 2002, 2004), som også egner sig til mikrodata på befolkningsniveau, konkret udmøntet i forbindelse med demografifaget på folkesundhedsvidenskabsstudiet i København (studiet i Esbjerg har også et demografifag). Dansk kvantitativ sociologi er desværre meget lavmælt, men den nyeste udvikling af sociologifaget ved Aalborg Universitet omfatter også demografi.

Den prædiktive demografi (højre side i Fig. 2) repræsenteres for tiden dels af Danmarks Statistiks årlige befolkningsprognoser (som siden 2002 har stratificeret på indvandrerstatus), dels af Finansministeriets DREAM-model, som er højaktuel i forbindelse med Velfærdskommissionen.

Min viden om den internationale situation er begrænset, men kontakter med de geografisk nærmeste demografiske forskningscentre (Rostock, Lund, Oslo) tyder på, at vi i Danmark både har meget at lære og noget at komme med. Max-Planck-Institut für demografische Forschung i Rostock (som har et seminarlokale opkaldt efter Westergaard) har sin vigtigste virksomhed opdelt i en afdeling for dødelighed, som er ganske matematisk og biologisk orienteret, og en afdeling for fertilitet, som arbejder mere traditionelt deskriptivt med interesse for socioøkonomiske determinanter. Det norske miljø ved Universitetet i Oslo og Statistisk Sentralbyrå arbejder med dyberegående analyser af fertilitetsvariation efter socioøkonomiske determinanter, med sofistikeret an- 
vendelse af moderne statistiske heterogenitetsmodeller. Miljøet ved Lunds Universitet fokuserer på historiske mikrostudier. Endelig bør nævnes en spændende forskningslinie ved INED-INSERM forskningsgruppen i Le KremlinBicêtre ved Paris, som kombinerer biologiske og samfunds- og adfærdsmæssige fertilitetsdeterminanter.

En gruppe interesserede blandt de nævnte "naboforskere" har i 2004 taget initiativ til dannelsen af et uformelt netværk med Danmarks Statistik som engageret medspiller. Forhåbentlig vil dette og andre initiativer muliggøre, at vi kan løfte arven efter Westergaards store indsats for dansk demografi.

\section{Litteratur:}

Andersen, O. 1985: Dødelighed og erhverv 1970-80. København: Danmarks Statistik.

Andersen, O., Laursen, L. \& Petersen, J. K. 2001: Dødelighed og erhverv 1981-1995. København: Danmarks Statistik.

Andersen, P. K. 1997: Multi-state models for event history analysis in clinical medicine and epidemiology. Doktorafhandling, Biostatistisk Afdeling, Københavns Universitet.

Browning, M. \& Ejrnæs, M. 2003: Consumption and Children. CAM Working papers 200206.

Danø, A. M., Ejrnæs, M. \& Husted, L. 2004: Do Single Women Value Early Retirement more than Single Men? CAM Working papers 2004-06.

de Gans, H. A. 1999: Population Forecasting 1895-1945. The Transition to Modernity. Dordrecht: Kluwer.

Hougaard, P. 1995: "Frailty models for survival data". I: Lifetime Data Anal. 1, 255-73.

Jacobsen, R. 2004: Mortality in Danish women: age, period and cohort analysis. Ph.D.dissertation, Department of Epidemiology, University of Copenhagen.

Jacobsen, R., Keiding, N. \& Lynge, E. 2002: “Long term mortality trends behind low life expectancy of Danish women". I: J. Epidemiol. Comm. Health 56, 205-208.

Jacobsen, R., von Euler, M., Osler, M., Lynge, E. \& Keiding, N. 2004: “Women's death in Scandinavia - what makes Denmark different?" I: Eur. J. Epid. 19, 117-121.

Jensen, T. K., Carlsen, E., Jørgensen, N., Berthelsen, J. G., Keiding, N., Christensen, K., Petersen, J. H., Knudsen, L. B. \& Skakkebæk, N. E. 2002: “Poor semen quality may contribute to recent decline in fertility rates". I: Human Reproduction 17, 1437-1440.

Juel, K. 2004: Dødeligheden i Danmark gennem 100 år. Statens Institut for Folkesundhed.

Keiding, N. 1987: “The method of expected number of deaths 1786-1886-1986". I: Int.Statist.Rev. 55, 1-20.

Keiding, N. 1990: "Statistical inference in the Lexis diagram". I:Phil.Trans.Roy.Soc.Lond.A. 332, 487-509.

Keiding, N. 2000: “Graphical representations in mortality measurement: Knapp, Zeuner, Becker, Lexis". I: Research Report 00/8, Department of Biostatistics, University of Copenhagen.

Knudsen, L. B. 1993: Fertility Trends in Denmark in the 1980s. A Register Based Sociodemographic Analysis of Fertility Trends. København: Danmarks Statistik. 
Knudsen, L. B. 1998: “The Danish Fertility Database“. I: Dan.Med.Bull. 45, 221-225.

Lexis, W. 1875: Einleitung in die Theorie der Bevölkerungsstatistik. Strassburg: Trübner.

Petersen, J. K. 2000: “The Danish Demographic Database - longitudinal data for advanced demographic methods". I: Research Report 15, Demografisk Forskningscenter, Odense.

Rubin, M. \& Westergaard, H. 1886: Landbefolkningens Dødelighed i Fyens Stift. Kjøbenhavn: Philipsen.

Rubin, M. \& Westergaard, H. 1890: Ægteskabsstatistik paa Grundlag af den sociale Lagdeling. Kjøbenhavn: Philipsen.

Scheike, T. 2002: Dynamic event history models. Doktorafhandling, Biostatistisk Afdeling, Københavns Universitet.

Scheike, T. 2004: "Time-varying effects in survival analysis". I: Handbook of Statistics 23 (ed. N. Balakrishnan \& C.R. Rao), Elsevier, pp. 61-85.

Vaupel, J. W., Manton, K. G. \& Stallard, E. 1979: “The impact of heterogeneity in individual frailty on the dynamics of mortality". I: Demography 16, 439-454.

Westergaard, H. 1882: Die Lehre von der Mortalität und Morbilität. Jena: Fischer.

Westergaard, H. 1898: “Oldingealderens Dødelighed“. I: Nat.øk.Tidsskr. 349-358.

Westergaard, H. 1901: Die Lehre von der Mortalität und Morbilität. Zweite Aufl., Jena: Fischer.

Westergaard, H. 1908: "The Horoscope of the population in the twentieth century". I: Bull.Int.Stat.Inst. 17, 103-118.

Westergaard, H. \& Nybølle, H. C. 1927: Statistikens Teori i Grundrids. 3. Udg., København: Gad.

Westergaard, T., Andersen, P. K., Pedersen, J. B., Frisch, M., Olsen, J. H. \& Melbye, M. 1998: "Testicular cancer risk and maternal parity: a population-based cohort study". I: Br J Cancer 77, 1180-5.

Wohlfahrt, J., Andersen, P. K., Mouridsen, H. T., Adami, H. O. \& Melbye, M. 1999: "Reproductive history and stage of breast cancer". I: Am. J Epidemiol. 150, 1325-30.

Yule, G. U. 1934: "On some points relating to vital statistics, more especially statistics of occupational mortality (with discussion)".I: J. R. Statist. Soc. 97, 1-84.

Zangenberg, C. U. \& Zeuthen, H. E. 1997: Den hoide hue. Hvad fører den til? København: Danmarks Statistik.

Niels Keiding

E-mail: nk@biostat.ku.dk 